\title{
Assessing and Including Students with Disabilities in Summer Programs
}

\author{
Linda Johnston Ed.D ${ }^{1}$, Betty McNulty Ed.D ${ }^{2, *}$, Merwin A. McCoy ${ }^{1}$, \\ Cheryl Robinson Ph.D ${ }^{1}$, Lawrence A. Beard ${ }^{3}$ \\ ${ }^{1}$ School of Education, University of Tennessee at Chattanooga \\ ${ }^{2}$ Health and Human Performance Department, University of Tennessee at Chattanooga \\ ${ }^{3}$ College of Education and Professional Studies, Jacksonville State University \\ *Corresponding author: lbeard@jsu.edu
}

Copyright $(0) 2013$ Horizon Research Publishing All rights reserved.

\begin{abstract}
Recreation and leisure activities are important to the quality of life for all individuals. Through various activities, individuals have opportunities to improve their overall health, self-concept, develop social skills and become part of a small community group. With the emphasis on including individuals with disabilities and good health within the community, it is important that all individuals are provided with this opportunity. Summer programs to include students with a diagnosed disability are becoming more accessible and available. Parents oftentimes look for opportunities for their children during the summer months, either in the forms of day, overnight camps or enrichment type activities. While many camps and summer programs exist specifically for students with a diagnosed disability, there are programs that are more inclusive and provide specific accommodations to assure successful inclusion of all types of children. Public institutions and entities are required by law to make summer programs available to all children. This paper will present some concrete steps to help ensure that all students, including students with disabilities, can, to the maximum extent appropriate, participate in the summer camp programs.
\end{abstract}

Keywords Summer Programs, Students With Disabilities, Assessment, Inclusion, Physical Education, Recreation

\section{Introduction}

The passage of Public Law 101-336 in 1990, the Americans with Disabilities Act (ADA) and then in 2008, the Americans with Disabilities Act Amendments (ADAA), provide individuals with disabilities protection against discrimination. Gargiulo (2010) stated that the intent of these laws is to provide all individuals with services they are legally entitled, including community based activities. A summer program affiliated with a public institution or entity cannot deny an individual with a diagnosed disability participation based on the disability. Accommodations must be made for an individual to take part in programs sponsored by these types of entities.

While many students have unlimited opportunities to become involved in local recreation and leisure time activities during the summer months, students with a diagnosed disability often struggle to find activities in which they can participate. Community resources are at a minimum, and support for individuals with disabilities to participate in such activities is simply not available.

ADA is the law that guarantees that every individual has the right to participate in any programs sponsored by public entities. In part, related to activities, ADA (2011) states:

"It shall be discriminatory to subject an individual or class of individuals on the basis of a disability or disabilities of such individual or class, directly, or through contractual, licensing, or other arrangements, to a denial of the opportunity of the individual or class to participate in or benefit from the goods, services, facilities, privileges, advantages, or accommodations of an entity" (available fromAMERICANS WITH DISABILITIES ACT OF 1990, AS

AMENDEDhttp://www.ada.gov/pubs/adastatute08.htm\#12 182.

In an effort to enhance and assure that individuals with a diagnosed disability have equal opportunity to experience the success of summer recreation and camp programs, it becomes the responsibility of the sponsoring entity to provide reasonable accommodations for an individual with a disability.

The term that should be viewed when making accommodations is "reasonable". Many communities have already addressed the facilities portion of the law such as adding accessible ramps, restrooms, widening of doors and Braille signs on doors. These are solutions to the term "reasonable accommodations" that make recreation 
accessible to all individuals. To accomplish this, the need to market the program and let the public know that all individuals have equal access, but certain developmental domains and core standards must be met for all students to enjoy summer programs.

Developmental domains consisting of physical, cognitive, social and emotional are essential to the overall well-being of a child total development that can be addressed in summer programs. Physical domains development will enable the child to in such activities that would use gross motor skills, such as horseback riding, swimming, hiking, rappelling and canoeing.

Cognitive development skills may be integrated across all domains. We do this by helping the child use problem solving activities, remembering the day to day activities, following schedules, expressing ideas in both verbal and written forms and visual and auditory perception.

Social development can be enhanced through the ways and means that the child interacts with their camp peers. These interactions can be structured within the activities so the child will have to interact in both an individual and group setting.

Emotional development will include the development of certain inter and intra personal skills. Interpersonal skills are helping the child to interact with other people and intrapersonal skills help the child to understand why he acts as he does in given situations.(DevelopmentStandards for Four year-olds, 2013) http://www.pacwcbt.pitt.edu/Curriculum/911-4\%20FP\%20a nd\%20Child\%20Development/Overheads-911-4\%20Foster \%20Parenting\%20and\%20Child\%20Development/OH\%20 5\%20Developmental\%20Domains.pdf

\section{Discussion}

To assure the best experience possible, accommodations for each developmental domain must be addressed. These specific accommodations must be integrated across all domains and individualized for each child.

Core performance based standards should be integrated with the developmental domains for all children. These standards are those designed to ensure safety and participation by all students. These are meshed with daily activities and developmental domains provided with both the summer camps and the individual in mind. Accommodations for core performance/developmental domain standards for a summer camp can include:

1). Cognitive Domains
a. follows basic health and safety rules
b. walks with the group
c. follows directions
d. learning the daily schedule

2). Affective domain/ self-help skills
e. personal trait development
f. complete personal care routines
g. dress/undress by him/herself

h. wash/dry hands without assistance

i. feed him/herself independently

j. participating/collaborating in group activities

3). Psychomotor domain/motor Skills

k. moves with balance and control independently

1. grips items

m. mobility training for children who are confined to a wheelchair

If children do not meet these developmental domain/core performance standards, parents must be given the opportunity for an assessment to determine if/and what accommodations may be necessary for their child to be included and have an enjoyable time in a summer program. An assessment does not have to be lengthy nor should it be as involved as one provided by the Local Education Agency (LEA) for placement in a special education program. This assessment should be informative and to the point. All assessments should include at a minimum: questions for the parents, a follow up interview with the parents, a copy of the child's current IEP (if available) and a letter from the physician documenting any issues that might prevent the child from participating in a summer program. This holistic approach will help the camp staff provide reasonable accommodations to help ensure success for the child in the summer program.

To determine what accommodations would best meet the needs of children to participate, the camp staff should come together as a group to discuss reasonable accommodations for the child to be successfully included in all camp activities. An assessment committee may be formed to conduct and review the assessment information provided by all parties involved and to make suggestions for ways these accommodations can be implemented in the total program.

Beard et al. (2011) states that reasonable accommodations can be made for any individual with little to no expense. Velcro is often used to hold an individual's fingers together by wrapping it around the fingers. Light tech communication boards can be made from poster board or wood with basic visual representations for individuals who have difficulty with communication and are not tied to a power source. Adaptive seating for recreational type activities can be made from netting or canvas, and text can be enlarged through the use of most word processing programs(Beard, L., Carpenter, L., \& Johnston, L. 2011).

Walker (1999) states that supports may vary from person to person. This is based on the needs of each individual. Supports can range from physically assisting an individual to enable them to take part in an activity or helping the individual acquire the skills or competencies necessary for an activity (Walker, 1999).

\section{Conclusion}

While many argue that the cost may be prohibitive for individuals with disabilities to be involved in community based recreation/camp activities, the benefits to a person's 
health and development far outweigh this argument. Kolbe (1992) identified 4 areas that a healthful, physically active and recreational lifestyle will assist: maximize personal health, prevent other health problems, reduce health care costs and assist in the health objectives of achieving health equity, eliminating disparities, and improving the health of all groups (Kolbe, 1992).

For a summer program to help the student in his/her core/developmental domains, the program will have to be carefully planned and executed by the professional staff using data from all areas of the assessments. Statistics from the Administration for Children and Families (2013) indicate that $12 \%$ of children receiving Headstart have a diagnosed disability ((http://www.acf.hhs.gov/programs/ohs/quick-fact) According to the National Center for Educational Statistics, (2013) in the 2009-2010 academic year, a total of $13.1 \%$ of the school aged population had a diagnosed disability (http://nces.ed.gov/fastfacts/display.asp?id=64). With these statistics in mind, students with diagnosed disabilities can no longer be excluded from summer programs and these programs will have to be able to make reasonable accommodations for these students.

\section{REFERENCES}

[1] Americans with Disabilities Act, As Amended, 1990:
Retrieved June 13, 2011 from http://www.ada.gov/pubs/adastatute08.htm\#12182

[2] Administration for Children and Families [Internet] Washington, DC: Administration for Children and Families (2013) [Cited2013 June 10]. Available from: http://www.acf.hhs.gov/programs/ohs/quick-fact

[3] Beard, L., Carpenter, L., \& Johnston, L. (2011).Assistive Technology for Communication. In Assistive Technology: Access for All Students (2nd edition). Boston: Pearson Publishing.

[4] Developmental Standards for Four Year Olds: http://www.pacwcbt.pitt.edu/Curriculum/911-\%20FP\%20an d\%20Child\%20Development/Overheads-911-4\%20Foster\% 20Parenting\%20and\%20Child\%20Development/OH\%205\% 20Developmental\%20Domains.pdf

[5] Gargiulo, R.M. \& Metcalf, D., (2010).Teaching in today's inclusive classrooms: a universal design for learning approach. Wadsworth, Cengage Learning, Belmont, CA.

[6] Kolbe L.J. (1992). As essential strategy to improve the health and education of America. Paper presented at the American Academy of Pediatrics Annual Meeting, San Francisco, CA.

[7] National Center for Educational Statistics [Internet] Washington, DC . National Center for Educational Statistics [2013] [Cited2013 June 10]. Available from: http://nces.ed.gov/fastfacts/display.asp?id=64

[8] Walker, P. (1999). Promoting inclusion in recreation and leisure activities: an information package. National Resource Center on Supported Living and Choice, Center on Human policy. Syracuse University. 